\title{
Gestão social em territórios do Programa Minha Casa, Minha Vida - ensaiando possibilidades
}

\section{Social management in "Minha Casa, Minha Vida" territories - building possibilities}

\begin{abstract}
Francisco Raniere Moreira da Silva ${ }^{a}$
${ }^{a}$ Mestre e Doutorando em Administração pela Universidade Federal da Bahia (NPGA-UFBA). Professor Assistente do Centro de Ciências Sociais Aplicadas da Universidade Federal do Cariri (CCSA/UFCA). Líder do Grupo de Pesquisa Laboratório Interdisciplinar de Estudos em Gestão Social (LIEGS-UFCA) e membro dos grupos de pesquisa Centro Interdisciplinar de Desenvolvimento e Gestão Social (CIAGS-UFBA) e Núcleo de Estudos sobre Poder e Organizações Locais (NEPOL-UFBA). Integrante do Observatório de Políticas Públicas para Territórios (OPPTE) e do Observatório da Formação em Gestão Social (OFGS). Tem experiência na área de Administração e Gestão Pública e Social, com ênfase nos temas Gestão Social, Gestão do Desenvolvimento Territorial, Governança Territorial, Arranjos Institucionais e Interorganizacionais, Política Habitacional e Política Urbana.); E-mail: raniere.moreira@ufca.edu.br
\end{abstract}

Recebido em: 26/10/2016 I Aceito em: 02/12/2016 


\title{
RESUMO
}

Este trabalho se propôs a investigar as possibilidades de construção de estratégias de gestão social dos territórios criados a partir do "Programa Minha Casa, Minha Vida" (PMCMV). Trata-se de um ensaio teórico que considera a questão habitacional como uma das principais expressões da problemática urbana contemporânea e analisa de que forma a gestão social pode contribuir nos processos de desenvolvimento territorial dos empreendimentos destinados à habitação de interesse social no Brasil. Propõe o delineamento de ações capazes de reduzir as desigualdades sociais provocadas pela segregação espacial e garantir a integração cidadã e inserção produtiva dos habitantes destes espaços e analisa as perspectivas para a implementação e sustentabilidade destas ações. São discutidos os principais problemas inerentes aos empreendimentos habitacionais do PMCMV e as possibilidades de superação destas questões por meio da gestão social e do protagonismo dos sujeitos locais. A análise aponta três grandes desafios a serem superados, quais sejam: o fortalecimento dos vínculos sociais e identitários, a ampliação da cidadania e a viabilização de condições dignas de trabalho e renda. Neste contexto, gestão social se apresenta como um caminho possível, seja incorporada como elemento central nos Projetos de Trabalho Social ou a partir de outras iniciativas endereçadas à construção do desenvolvimento territorial e melhoria das condições de vida.

Palavras-chave: Gestão Social. Desenvolvimento Territorial. Habitação Social. Política Habitacional. Minha Casa, Minha Vida.

\begin{abstract}
This study aimed to investigate the possibilities of building strategies of social management by the territories created in the context of "Minha Casa, Minha Vida" (PMCMV). This is a theoretical essay that considers the housing as one of the main expressions of contemporary urban issues and analyzes how social management can contribute in territorial development processes of the social housing projects in Brazil. Proposes the design of actions that reduce social inequalities caused by the spatial segregation and ensure citizen integration and productive insertion of the inhabitants of these areas and analyzes the prospects for the implementation and sustainability of these actions. The main problems related to housing projects of PMCMV and the possibilities of overcoming these issues through social management and the role of local actors are discussed. The analysis points out three major challenges to be overcome: strengthening social and identity links, expansion of citizenship and provide decent work and income. In this context, social management is presented as a possible way, is incorporated as a key element in social work projects or from other initiatives addressed to the construction of territorial development and improvement of living conditions.
\end{abstract}

Key Words: Social Management. Territorial Development. Social Housing. Housing Policy. "Minha Casa, Minha Vida". 


\section{Introdução}

Este trabalho se insere no contexto de discussão da problemática urbana de maneira geral e, de modo particular, das políticas habitacionais que, ao produzirem moradia, produzem novos territórios. Lança o olhar sobre os territórios intraurbanos resultantes das políticas habitacionais brasileiras, especialmente os empreendimentos residenciais destinados à habitação de interesse social no âmbito do Programa Minha Casa, Minha Vida (PMCMV) - Faixa $1^{1}$, programa do governo federal brasileiro destinado à produção habitacional para famílias de baixa renda.

O foco é a provisão habitacional e a gestão social dos territórios produzidos a partir dela. Em que pese a importância das outras tantas agendas relacionadas à questão urbana, reconhecidas como componentes do direito à cidade e reclamadas por diversos movimentos sociais, parte-se do entendimento de que é a partir da habitação, e nos territórios por ela produzidos, que muitos dos problemas urbanos vão se expressar. É também a partir destes territórios que podem ser construídas algumas alternativas de mitigação dos referidos problemas.

Como aponta Maricato (2013, p.22), ao longo da história recente do Brasil, os processos de mobilização social e luta popular pela consolidação do Estado de direitos em geral, e do Direito à moradia, em particular lograram alguns resultados positivos, relacionados à garantia de direitos, implementação de políticas e institucionalização de mecanismos de participação e controle social. Entre estes resultados estão: o reconhecimento, na Constituição Federal de 88, da função social da propriedade da terra e do direito à cidade, a aprovação do Estatuto da Cidade pela Lei 10.257, em 2001, a criação do Ministério das Cidades em 2003 e do Conselho das Cidades em 2004 e a realização das Conferências Nacionais das Cidades em 2003, 2005 e 2007.

\footnotetext{
${ }^{1}$ Modalidade do Programa Minha Casa, Minha Vida responsável pela produção de empreendimentos habitacionais destinados às famílias com renda mensal bruta de até $R \$ 1.800,00$. Nesta modalidade, os subsídios do Programa às famílias para custeio do imóvel podem chegar até $90 \%$.
}

Ciência e Sustentabilidade - CeS / Juazeiro do Norte v. 2, n. 2, p. 84-105, jan/jun 2016 
No tocante à questão habitacional no Brasil, destacam-se também alguns acontecimentos importantes como a instituição da nova Política Nacional de Habitação (PNH) em 2004, a criação, pela Lei no 11.124/2005, do Sistema Nacional de Habitação de Interesse Social (SNHIS), do Fundo Nacional de Habitação de Interesse Social (FNHIS) e do Conselho Gestor do FNHIS, e a instituição do Programa Minha Casa, Minha Vida (PMCMV) pela Lei oㅜ 11.977/2009.

Resultado concreto e localizado deste processo são os territórios surgidos com a produção de empreendimentos habitacionais na periferia das cidades brasileiras, cuja inserção urbana é precária.

Por tais razões, este texto se propõe a analisar teoricamente as possibilidades de construção de estratégias de gestão social dos territórios surgidos no contexto das políticas habitacionais do Brasil recente. $O$ trabalho parte da seguinte indagação: Como a gestão social pode contribuir para o delineamento de estratégias de desenvolvimento dos territórios do Programa Minha Casa, Minha Vida? O pressuposto assumido é o de que, como campo de conhecimento e de práticas ancorado na ação coletiva, participação e ampliação da cidadania, a gestão social aporta elementos úteis ao desenvolvimento e melhoria das condições de vida destes territórios. Não obstante a importância dos aspectos físicos e urbanísticos que estruturam os territórios de habitação social, a discussão aqui travada é endereçada à dimensão social do desenvolvimento territorial, relacionada às formas de ação coletiva de que se pode lançar mão na construção de estratégias de desenvolvimento.

O trabalho está organizado em mais quatro seções, além desta introdução. A seção que segue apresenta uma caracterização da política de habitação social brasileira. Em seguida são discutidos alguns problemas relacionados à implementação da política e de seus instrumentos, sobretudo no que diz respeito à segregação socioterritorial que tem provocado. Por fim, são delineadas algumas possibilidades de construção da gestão social do território, a partir da educação para a cidadania e do protagonismo social dos sujeitos locais, bem como são tecidas algumas considerações finais. 


\section{Habitação Social no Brasil e o Programa Minha Casa, Minha Vida - percurso histórico e debate acadêmico}

Uma das maiores expressões da problemática urbana contemporânea é a questão habitacional. Em que pese a importância das outras tantas agendas relacionadas à questão urbana e reclamadas pelos diversos movimentos de luta pelo direito à cidade, como o transporte e mobilidade urbana $e$ as questões ambientais, compreende-se que é a partir da habitação, e nos territórios por ela produzidos, que muitos dos outros problemas urbanos vão se expressar. É também a partir destes territórios que podem ser construídas algumas alternativas.

Por muitos anos, o tema da habitação no Brasil e seus processos de produção, comercialização e financiamento ficaram restritos ao domínio do mercado. Segundo Bonduki (1994, p.711) é no governo Vargas que o Estado passa a intervir na questão habitacional, como parte da estratégia de impulsionar a formação e fortalecimento de uma sociedade de cunho urbano-industrial no país.

Ao tratar das origens da habitação social no Brasil, Bonduki (1994, 2011) afirma que, embora as políticas habitacionais tenham se intensificado nas últimas décadas do século $X X$, a intervenção estatal na agenda habitacional tem início ainda lá atrás, no governo Vargas. Para o autor, já no início do século XX a demanda por moradia no país começou a se intensificar, transformando-se em questão social. Esse período coincide com a intensificação do processo de urbanização brasileiro, resultado da industrialização tardia do país (MARICATO, 1997).

Com a crise internacional de 1929 e a Revolução de 1930 no Brasil, mudouse a lógica de atuação do governo nas políticas sociais. Em meio à crise econômica internacional, a altos índices de desemprego e necessidade de legitimação, o governo de Vargas adotou medidas de modernização do Estado e construção de uma identidade nacional. A política social do governo buscou atuar em dois âmbitos centrais: a garantia de ações de previdência e assistência social para os trabalhadores e melhoria das condições de vida. Assim, a habitação social passou a ter fundamental importância. 
Se por um lado os investimentos em habitação social assumiam papel vital no combate à crise econômica e serviam de meio para o processo de industrialização do País, por outro foram o elemento formador de uma nova classe trabalhadora, base de sustentação política (BONDUKI, 1994, p.716). Além disso, com a promulgação da Lei do Inquilinato em 1942, que congelou o valor dos aluguéis, o modelo rentista adotado pelo setor privado não foi efetivo no atendimento da demanda habitacional e, portanto, o Estado deveria intervir de forma direta na oferta de condições básicas de sobrevivência à população. Em meio às discussões sobre o papel do Estado no tema habitacional, surgiram então duas possibilidades: oferecer casa própria ou habitações de aluguel. O posicionamento do então presidente Getúlio Vargas foi pela casa própria, uma vez que ao terem acesso a esse benefício, trabalhadores de baixa renda estariam dignificando seu trabalho honrado.

Diversos são os elementos de destaque na trajetória histórica das políticas habitacionais brasileiras, dentre eles: (1) a criação, em 1946, da Fundação da Casa Popular (FCP) em 1946 - primeiro órgão público federal dedicado à questão da moradia; (2) a criação, em 1964, do Banco Nacional de Habitação (BNH) - à época, a principal instituição pública de desenvolvimento urbano do país cuja atuação se dava sobretudo na gestão do FGTS e na formulação e implementação do Sistema Financeiro da Habitação (SFH) e do Sistema Financeiro do Saneamento (SFS). BNH foi extinto em 1986, período de forte crise e fragmentação institucional na política habitacional do Brasil; (3) A criação da Secretaria de Política Urbana SEPURB e as propostas de reforma do setor habitacional em 1995, que culminaram com a criação da Secretaria de Estado de Desenvolvimento Urbano da Presidência da República, em 1999. Não se pretende aqui aprofundar o debate sobre os distintos momentos históricos das políticas habitacionais no Brasil, esta tarefa já foi realizada por Bonduki (1994, 2008, 2011). O resgate aqui é feito no intuito de evidenciar as bases históricas, institucionais, econômicas e políticas que confluíram para o desenho recente de inserção do Estado na questão habitacional. Vale ressaltar, com este intento, as medidas de caráter mais proativo assumidas pelo governo federal brasileiro na última metade dos anos 90 e início dos anos 2000.

O cenário recente da política habitacional brasileira, sobretudo a partir do primeiro mandato do Governo Lula (2003-2007) é marcado pela ampliação dos 
financiamentos habitacionais e pela constituição de importantes marcos institucionais e regulatórios, como a criação do Ministério das Cidades, em 2003, seguido da aprovação da Política Nacional de Habitação e do Plano Nacional de Habitação (PlanHab), da constituição do Sistema Nacional de Habitação de Interesse Social (SNHIS) e, mais recentemente, do lançamento do Programa Minha Casa Minha Vida (PMCMV). O PMCMV é um Programa habitacional do governo federal brasileiro que tem por finalidade criar mecanismos de incentivo à produção $e$ aquisição de novas unidades habitacionais ou requalificação de imóveis urbanos e produção ou reforma de habitações rurais destinadas a famílias de várias faixas de renda (BRASIL, 2009).

Neste mesmo período observam-se profundas transformações nas políticas urbanas e de habitação, num cenário econômico de massivos investimentos, tanto públicos quanto privados, na produção habitacional (DENALDI, 2012). Todavia, em que pese o panorama das conquistas sociais, sobretudo em termos institucionais e de mecanismos de participação e controle social, a orientação tomada na operacionalização destas conquistas e direitos seguiu outros rumos (ROLNIK, 2013b; MARICATO, 2013; VAINER, 2013). A reforma fundiária/imobiliária, centro da agenda de reforma urbana, foi esquecida (Maricato, 2013). As medidas de combate à pobreza iniciadas pelo Governo Lula e continuadas pelo Governo Dilma Rousseff foram direcionadas muito mais ao fortalecimento do mercado interno, com a ampliação da renda e o incentivo ao consumo. Em termos de infraestrutura econômica e social, investimentos vultosos foram executados no âmbito do Programa de Aceleração do Crescimento - PAC I e II e do Programa Minha Casa Minha Vida - PMCMV (Maricato, 2013), com notável protagonismo do setor privado na condução das políticas. Exemplo disso é a atuação da Caixa Econômica Federal como principal agente executor do PMCMV, somado à ação de construtoras e outros players do mercado imobiliário na definição dos rumos da política habitacional.

Como afirma Rolnik (2013a) os modelos e instituições de gestão participativas não foram incorporados no desenho e processos decisórios das políticas e programas recentes de financiamento do desenvolvimento urbano - como o PAC e o PMCMV - que ganharam enorme impulso nos últimos cinco anos, deslegitimando os 
fóruns e arenas de participação existentes (como conselhos de habitação e de cidades) como lócus de elaboração e decisão.

Este contexto de transformações políticas, econômicas e sociais no campo da habitação desperta, ou retoma, o interesse acadêmico pelas questões relacionadas à problemática habitacional.

De diferentes formas e com diferentes focos e objetivos, pesquisadores têm analisado a política habitacional do Brasil recente e o Programa Minha Casa, Minha Vida, seu principal instrumento, evidenciando contornos, avanços, limites, dilemas, possibilidades e desafios. Destacam-se aqui os trabalhos de NETO; MOREIRA; SCHUSSEL, 2012; DRUMOND; SILVEIRA; SILVA, 2014; SANTOS et al., 2014; RIZEK, SANTO AMORE; CAMARGO, 2014; QUIRINO et al., 2015.

Este artigo parte do reconhecimento destes desafios e se propõe a contribuir na busca de alternativas e na construção de estratégias que sejam catalisadoras de efeitos positivos do PMCMV nos territórios por ele criados.

\section{3 “Isso aqui é lugar nenhum!" - Segregação socioespacial e inserção urbana precária no Programa Minha Casa, Minha Vida (PMCMV)}

A operacionalização das conquistas e direitos relacionados à moradia digna tem se dado, em larga parte, segundo uma lógica neoliberal (Vainer, 2013) pautada pelo capital financeirizado, ampliando a gentrificação urbana e a segregação socioespacial. Evidência concreta disso são boa parte dos empreendimentos habitacionais construídos pelo PMCMV, erguidos em terrenos localizados nas franjas - quando não apartados - do tecido urbano, estes espaços sem-cidade configuram territórios de inserção urbana precária.

Desde que foi criado, em 2009, o PMCMV tem sido objeto de diversas análises, dentro e fora da academia. Cardoso e Lago (2013) já discutiram os efeitos territoriais do Programa Minha Casa Minha Vida, destacando as principais lacunas e deficiências do Programa.

As diversas críticas feitas ao MCMV estão principalmente relacionadas à insuficiência no atendimento à demanda prioritária - famílias com renda de 1 a 3 
salários mínimos - (ARANTES; FIX, 2009; MARQUES; RODRIGUES, 2013), à segregação socioespacial provocada pela localização dos empreendimentos (CARDOSO; LAGO, 2013; MARQUES; RODRIGUES, 2013; SOARES et al., 2013; SANTOS et al., 2014; MOURA, 2014) e à forma relação com o mercado (BONDUKI, 2009; DENALDI, 2012; MARICATO, 2009).

Os estudos conduzidos por Soares et al. (2013) e Moura (2014), respectivamente em Uberaba-MG e Natal-RN, demonstram como o comportamento do mercado imobiliário, atrelado a interesses do poder público municipal, orienta a localização dos empreendimentos do PMCMV e interfere na articulação entre as políticas urbana e habitacional. Pela análise da localização e da inserção urbana dos empreendimentos, observa-se a carência de serviços e infraestrutura, determinante da segregação da população residente.

De acordo com Santos et al. (2014), o PMCMV atende precariamente a população situada nas menores faixas de renda, de maneira que o acesso à moradia é limitado pelo não atendimento à demanda prioritária, pela dificuldade dos contemplados em arcar com os custos da moradia, pela localização periférica dos empreendimentos, o que impõe dificuldades de acesso à infraestrutura e serviços básicos e a oportunidades de trabalho e renda. Para as autoras,

[...] apesar de inovar na implementação de política habitacional voltada para a população situada nas menores faixas de renda, o PMCMV garante precariamente 0 direito constitucionalmente instituído, não sendo exatamente um exemplo de autonomia, mas de concretização de interesses econômicos da indústria da construção civil e do mercado imobiliário, parceiros estratégicos das forças políticas à frente do governo e que, em tempos de crise, potencializam seus lucros através da ampliação de mercados. (SANTOS et al., 2013, p. 714).

Como pode ser observado, o problema com os empreendimentos construídos pelo PMCMV repousa sobretudo nas condições de habitabilidade do território, o que envolve, além da estrutura física de construção da casa, o acesso a serviços de infraestrutura e a equipamentos e serviços básicos como saúde, educação, segurança e transporte público. À precariedade dos empreendimentos habitacionais, soma-se a fragilidade das condições de inserção no ambiente urbano e das 
conexões estabelecidas com a cidade. Outra questão problemática nestes territórios está relacionada à falta de coesão social, onde pessoas das mais variadas origens, com trajetórias, culturas e interesses diversificados, que nunca conviveram juntas, compartilham agora um mesmo espaço

Os territórios do Minha Casa, Minha Vida podem ser interpretados como cidades de chegada, recortes urbanos que configuram espaços de transição e inserção na esfera urbana. Como afirma Saunders (2013, p.11) "A cidade de chegada é povoada por pessoas em transição - transformando as pessoas de fora em cidadãos centrais e essenciais com futuros sociais, econômicos e políticos sustentáveis na cidade".

Para o autor, o futuro destes territórios - de chegada - e a forma com seus cidadãos se relacionarão com a "cidade central" em muito dependerão da forma como eles são apropriados nas políticas públicas e nos projetos de intervenção. $\mathrm{Na}$ concepção de Saunders (2013), estas cidades de chegada possuem funções específicas a serem consideradas, quais sejam: 1) a manutenção de uma rede ou teia de relações humanas que Ihe deem identidade; 2) o estabelecimento urbano, com a garantia de todos os direitos sociais, e; 3) a viabilização de caminhos de mobilidade social.

Um olhar sobre os territórios do Minha Casa, Minha Vida, à luz das provocações de Saunders (2013), aponta a necessidade de construção de estratégias integradoras que articulem os diversos atores e sujeitos locais na discussão dos problemas do território e estruturação de ações convergentes, que garantam condições dignas de moradia, reduzam as precariedades de inserção urbana e sejam geradoras de transformação social e bem-estar coletivo. Ganham destaque aqui o protagonismo dos sujeitos locais e a tomada de decisões coletivas.

A gestão social surge então como possibilidade teórica e prática para inspirar projetos e ações de desenvolvimento local, que questionem a lógica inerente ao processo de globalização contemporânea, seja nos territórios do Minha Casa, Minha Vida, ou em outros recortes territoriais. Neste sentido, a seção que segue apresenta um breve panorama da gestão social, com o intuito de investigar as possibilidades de sua aplicação nos territórios do Minha Casa, Minha Vida. 


\section{A Construção da Gestão Social dos Territórios do PMCMV}

\subsection{Situando o debate teórico acerca da gestão social do território}

A gestão social tem sido discutida em diversos estudos conduzidos por pesquisadores brasileiros que contribuem para as tentativas de delimitação deste campo teórico. Entre estes estudos destacam-se os de Tenório $(1998,2008)$, Fischer (2002, 2007), França Filho (2003, 2008), Boullosa e Schommer (2008, 2009), Araújo $(2012,2014)$, Cançado $(2011,2014)$, Cançado, Pereira e Tenório (2013), entre outros.

Abordar o tema da gestão social remete a uma polissemia de conceitos e possibilidades interpretativas. Pode ser compreendido como uma nova possibilidade de gestão (Cançado, 2014) ou, de acordo com Fischer (2007) como gestão do futuro.

Fischer (2002, p.31) afirma que a gestão social é um campo em construção. Essa definição encontra coro nos trabalhos de (Araújo, 2012; Boullosa, 2009; Boullosa \& Schommer, 2008, 2009; Fischer \& Melo, 2006; França Filho, 2003, 2008). Tal construção não se dá sem conflitos e embates de ideias e propostas.

Analisando os principais estudos realizados sobre o tema é possível observar diferentes concepções e linhas de pensamento que orientam a construção do conhecimento em / sobre a gestão social. As diversas propostas de Tenório, Cançado e outros estudiosos do tema, por exemplo, vão na direção da delimitação do campo teórico da gestão social e sua institucionalização como campo de conhecimento e de práticas, distinto, e questionador, da gestão tradicional, referida como gestão estratégica. Nesta perspectiva, a gestão social surge como modelo alternativo de gestão. Seguindo por outro caminho, Fischer $(2002,2007)$ oferece uma visão cuja preocupação central é a mobilização de processos de gestão social, bem como de contextos territoriais e arranjos institucionais e interorganizacionais que os possibilitem. Em um esforço de síntese, apresenta-se aqui um panorama desta construção conceitual com vistas a situar o debate contemporâneo sobre o tema, sem pretensão de esgotá-lo. 
Tenório (1998, 2008) afirma que a gestão social possui um caráter democrático, sendo que a esfera pública é o espaço e a linguagem é o caminho que permitem sua existência. O autor define a gestão social como processo gerencial dialógico em que a autoridade decisória é compartilhada entre os participantes da ação, onde o termo social qualifica a gestão, inaugurando um espaço de relações sociais onde todos possuem o direito de fala, sem coação. Esta concepção está fortemente ancorada nos construtos de cidadania deliberativa e agir comunicativo de Habermas. Para o autor, a gestão social pode ser compreendida como contraponto à gestão estratégica.

Em um esforço de delimitação conceitual, Cançado, Tenório e Pereira (2011, p.697) apresentam a gestão social como processo de tomada de decisão coletiva, sem coerção, baseado na inteligibilidade da linguagem, na dialogicidade e no entendimento esclarecido como processo, na transparência como pressuposto e na emancipação enquanto fim último.

Uma aproximação teórica para a gestão social é apresentada em Cançado (2014, p.81), com base nas proposições de Cançado (2013) e Cançado, Pereira e Tenório (2013). Segundo o autor, a gestão social parte do Interesse Bem Compreendido, acontece na Esfera Pública e tem como objetivo a Emancipação.

Seguindo um raciocínio um pouco diferente, Fischer (2002) elabora outra concepção de gestão social. A autora utiliza o construto gestão do desenvolvimento social, entendendo-o como processo de gestão, campo de conhecimento e espaço de práticas. Para a caracterização do campo e identificação dos seus processos e paradoxos, tece cinco proposições.

Na primeira proposição, a gestão do desenvolvimento social é colocada como "um processo de mediação que articula múltiplos níveis de poder individual e social" e possui uma "[...] carga potencial de conflito de interesses entre atores envolvidos e entre escalas de poder." (Fischer, 2002, p.27). A segunda proposição trata da caracterização da gestão do desenvolvimento social como "campo de conhecimento e espaço de práticas híbridos e contraditórios. A cooperação não exclui a competição; a competitividade pressupõe articulações, alianças e pactos” (p.28). A outra proposição afirma que referido campo é orientado por valores e pela ética da responsabilidade que deve atender aos imperativos da eficácia e eficiência. 
Caracterizadas por fluidez, agilidade e inovação, as organizações e interorganizações de cunho social enfrentam desafios e correm sérios riscos de insustentabilidade e extinção. Como quaisquer outras organizações, devem mapear necessidades, delinear estratégias consequentes, desenvolver planos, gerir recursos escassos, [...] Prestar contas à sociedade, avaliar processos e resultados e regular ações são também tarefas essenciais do gestor eficaz. No caso de organizações de desenvolvimento social, a eficiência é função de efetividade social, isto é, da legitimidade conquistada." (FISCHER, 2002, p.28).

$\mathrm{Na}$ quarta proposição, a autora afirma que a gestão do desenvolvimento social inclui também a gestão de redes e de relações pessoais, mutáveis e emergentes, marcada pelo estilo e comportamento das pessoas, pela história do gestor, pela capacidade de interação e pela subjetividade (p.28). Finalmente, a quinta proposição aborda a dimensão cultural da gestão social e alude à importância do contexto cultural que a conforma e para o qual contribui. "O gestor social é um gestor do simbólico e do valorativo, especialmente quando se trata de culturas locais e da construção de identidades" (p.28).

Pode-se perceber que o debate e a ação sobre a dimensão territorial do desenvolvimento e da gestão tem lugar em um contexto de crescente globalização, da economia e da sociedade, com as consequentes contrapartidas na defesa do "local" e dos respetivos traços de singularidade e de especificidade que o caracterizam e identificam. No entanto, como defende Brandão (2012),

\begin{abstract}
Atualmente, se, por um lado, vivemos uma nova e intensa emergência dessa temática e a valorização da dimensão território, como talvez nunca tenha ocorrido nas ciências sociais, por outro, nota-se, em grande parte da literatura especializada, a completa banalização das questões que, malgrado sua natureza estrutural, histórica e dinâmica, foram deslocadas para o lugar-comum do voluntarismo, cristalizando um grande consenso, um verdadeiro "pensamento único localista" (p.12).
\end{abstract}

O autor alerta para os riscos, sobretudo de reducionismo, em desconsiderar as diversas escalas intermediárias entre o local e o global, muitas delas estruturantes. A partir desse pensamento, entende-se a necessidade de pensar a gestão socioterritorial a partir de suas singularidades e forças endógenas, mas sem 
perder de vista fatores decisivos estruturantes, "exógenos" à localidade, especialmente no contexto capitalista, que recorrentemente aprofunda e complexifica a divisão social do trabalho, em todas as suas dimensões, inclusive a espacial (Brandão, 2012, p.30).

Fischer (2002) admite que a gestão social é forjada por relações transescalares entre atores locais e de outras escalas, com níveis de poder assimétricos, cuja associação se faz pela complementaridade. Estas relações, complexas por sua própria natureza, inauguram novos desenhos organizativos e novas formas de gestão (Fischer, 2002, p.13). Tal concepção tem uma forte ancoragem no território e na construção de estratégias de desenvolvimento que articulem os atores locais e outros atores interinstitucionais e interorganizacionais com projetos para o território.

Todavia, buscar o delineamento de ações convergentes entre tais atores implica observar as diversas relações de poder espacialmente localizadas, entre sujeitos com interesses e visões de mundo distintas, não obstante as tensões, embates e conflitos inerentes a este processo. Assim, construir a gestão social do território demanda observar não apenas a substancia da gestão, mas a relação entre os agentes envolvidos, a construção de espaços de negociação e os vários papéis desempenhados pelos agentes no processo.

\subsection{Em busca de caminhos possíveis}

O panorama até aqui apresentado descortina um conjunto de possibilidades reais de utilização de premissas da gestão social para fomentar processos de desenvolvimento territorial nos empreendimentos habitacionais do Programa Minha Casa, Minha Vida. Neste percurso, a educação para a participação e a integração cidadã podem ser apontadas como caminhos para o fortalecimento da cidadania e o aumento do capital social local, dimensões fundamentais da gestão social e do desenvolvimento dos territórios. Outrossim, a sustentabilidade das estratégias de gestão social do território requer ancoragem em condições dignas de vida, de 
maneira que, sem um amplo investimento em integração socioprodutiva e criação de alternativas dignas de trabalho e renda, o desenvolvimento territorial que se faz é incompleto.

Em termos práticos, e em se tratando de uma política pública já consolidada, é importante identificar as possibilidades de aproximação com a gestão social no âmbito do arcabouço institucional que regulamenta a política habitacional e orienta a sua execução. Além disso, aponta-se a necessidade de investigar iniciativas em curso que já lancem mão de estratégias de gestão social para a promoção do desenvolvimento dos territórios do Minha Casa, Minha Vida.

No que diz respeito ao arcabouço institucional, observa-se que um espaço propício à utilização da gestão social pode ser encontrado nos Projetos de Trabalho Social a serem implementados nos empreendimentos habitacionais.

O Programa Minha Casa, Minha Vida - Faixa 1 possui como componente básico o Trabalho Social, regulamentado pela Portaria 21/2014 do Ministério das Cidades e destinado a empreendimentos de habitação de interesse social, com o objetivo de promover a participação social, a melhoria das condições de vida, a efetivação dos direitos sociais dos beneficiários e a sustentabilidade da intervenção. De acordo com a referida Portaria, o Trabalho Social

[...] compreende um conjunto de estratégias, processos e ações, realizado a partir de estudos diagnósticos integrados e participativos do território, compreendendo as dimensões: social, econômica, produtiva, ambiental e político-institucional do território e da população beneficiária, além das características da intervenção, visando promover o exercício da participação e a inserção social dessas famílias, em articulação com as demais políticas públicas, contribuindo para a melhoria da sua qualidade de vida e para a sustentabilidade dos bens, equipamentos e serviços implantados. (BRASIL, 2014).

Os Projetos de Trabalho Social são de responsabilidade do poder público local onde está situado o empreendimento ou, no caso em que o Governo do Estado aportar contrapartidas, sua responsabilidade deve ser definida entre os entes públicos envolvidos. Em qualquer das situações, os projetos devem prever ações 
estruturadas em três grandes eixos, quais sejam: Mobilização e Organização Comunitária; Educação Sanitária e Ambiental; e Geração de Trabalho e Renda.

Tais eixos guardam estreita relação com os aspectos relacionados à gestão social, o que reforça a pertinência de sua utilização como elemento central dos processos de desenvolvimento dos territórios do Minha Casa, Minha Vida. Diversas são as experiências de trabalho social já testadas e consolidadas em empreendimentos habitacionais situados em distintos contextos urbanos brasileiros, conduzidos por governos municipais ou por organizações contratadas para tal finalidade, com aporte de recursos da Caixa Econômica Federal.

Para além da questão já institucionalizada do Trabalho Social em empreendimentos de habitação de interesse social, diversas iniciativas pontuais de desenvolvimento territorial têm sido implementadas em alguns empreendimentos desde a criação do PMCMV. Trata-se de ações fomentadas por organismos como o Ministério das Cidades, a CAIXA e o PNUD, e executadas por governos locais, universidades, ONGs, entre outras entidades, com resultados que, embora localizados, possuem potencial de reaplicabilidade e podem aportar inovações úteis à estruturação de estratégias de desenvolvimento territorial em diversos contextos. Um exemplo destas iniciativas é o Programa de Desenvolvimento Integrado e Sustentável de Territórios (DIST), criado em 2013 sob a Coordenação da Caixa Econômica Federal e executado em diferentes empreendimentos no Brasil. O DIST propõe um conjunto de intervenções no território estruturadas em quatro eixos, quais sejam: governança territorial, dinamização econômica, gestão ambiental e promoção sociocultural. A experiência de DIST na Bahia foi alvo de análise e discussão de Fischer, Silva e Soares (2015).

Pode-se perceber que, embora de maneira implícita, a gestão social está presente e permeia considerável parte das iniciativas de desenvolvimento territorial que tem sido construídas e testadas no âmbito dos empreendimentos habitacionais do Programa Minha Casa, Minha Vida, seja pela via do Trabalho Social ou por projetos isolados. Todavia, é importante que se empreenda um esforço sistemático de pautar a sua pertinência e centralidade nestes processos. 


\section{Considerações Finais}

Tecer uma discussão sobre os territórios surgidos a partir dos empreendimentos do Programa Minha Casa, Minha Vida - Faixa 1, implica necessariamente em reconhecer os avanços em termos de política habitacional e provisão de moradia, mas também os inúmeros problemas inerentes ao Programa, seja os relacionados à forte imposição da agenda mercadológica de especulação imobiliária, ou os que dizem respeito à insuficiência no atendimento à demanda prioritária e às precariedades de inserção urbana dos empreendimentos.

Todavia, não há como desconsiderar também que os territórios do Minha Casa, Minha Vida são fato e reúnem milhares de famílias que precisam, entre outras coisas, serem reconhecidas como cidadãos de direitos, terem acesso a equipamentos e serviços básicos, bem como a fortes dignas de trabalho e renda. Como cidades de chegada, estes territórios precisam se integrar e criar conexões com a cidade estabelecida e seus equipamentos e fluxos. Isso impõe uma complexa agenda de intervenções no território, com vistas ao seu desenvolvimento.

A partir do panorama apresentado, é possível afirmar que, em que pese os problemas já debatidos, vislumbram-se possibilidades de superação das dificuldades e de construção de alternativas capazes de promover a efetiva integração cidadã e inserção produtiva dos sujeitos que ali residem. Neste contexto, gestão social se apresenta como um caminho possível, seja incorporada como elemento central nos Projetos de Trabalho Social ou a partir de outras iniciativas endereçadas à construção do desenvolvimento territorial e melhoria das condições de vida.

Todavia, há que se tomar cuidado com riscos da passionalidade, seja na intervenção feita no território ou na sua observação, porque a construção da gestão social do território pode ser muito sedutora na proposta e nas conquistas almejadas, por vezes impondo uma sensação de êxito total e mascarando problemas estruturais exógenos à localidade, característicos da cidade contemporânea e dos territórios que a conformam.

Não foi intenção deste trabalho aprofundar o debate sobre as relações entre a gestão social e o trabalho social em empreendimentos de habitação de interesse 
social, tampouco mapear as iniciativas de desenvolvimento territorial executadas no âmbito do Minha Casa, Minha Vida. A finalidade do texto se restringiu a identificar possibilidades de aplicação da gestão social para o desenvolvimento dos territórios do Minha Casa, Minha Vida, com o devido cuidado de não tomá-la como panaceia.

Por fim, alguns questionamentos se colocam: Como promover a gestão social dos territórios do Minha Casa, Minha Vida? Como fortalecer os vínculos de identidade territorial e coesão social nestes empreendimentos? Como estruturar processos de integração cidadã e inserção socioprodutiva para estas populações? Ao invés de respostas prontas ou um mapa de ação acabado, o que fica são indagações que podem inspirar reflexões presentes e investigações futuras.

\section{REFERÊNCIAS}

ARANTES, Pedro; FIX, Mariana. Como o governo Lula pretende resolver o problema da habitação: alguns comentários sobre o pacote habitacional Minha Casa, Minha Vida, Correio da Cidadania. 2009. Disponível em:

$<$ http://www.correiocidadania.com.br/index.php?option=com_content\&view=category \&layout=blog\&id=66\&ltemid=171 >. Acesso em: 20/06/2015.

ARAUJO, Edgilson. Gestão Social. In: BOULLOSA, Rosana. Dicionário para a formação em gestão social. Salvador: CIAGS/UFBA, 2014.

. (In)consistências da gestão social e seus processos de formação: um campo em construção. Tese de doutorado em Serviço Social. Pontifícia Universidade Católica de São Paulo, Programa de Estudos Pós-Graduados em Serviço Social, São Paulo: PUC São Paulo, 2012.

\section{AUGÉ, Marc. Não-Lugares: introdução a uma antropologia da} supermodernidade. São Paulo: Papirus, 1994.

BONDUKI, Nabil. Origens da Habitação Social no Brasil. Análise Social, Lisboa, v.29, n.127, p. 711-732, 1994.

. Política habitacional e inclusão social no Brasil: revisão histórica e novas perspectivas no governo Lula. Revista Eletrônica de Arquitetura e Urbanismo [arq.urb], v.1, p.70-104, 2008. 
Origens da habitação social no Brasil: arquitetura moderna, lei do inquilinato e difusão da casa própria. (6 ed). São Paulo: Estação Liberdade/ FAPESP, 2011.

BOULLOSA, Rosana; SCHOMMER, Paula. Limites da natureza da inovação ou qual o futuro da gestão social? In: Encontro da Associação Nacional de Pós-Graduação e Pesquisa em Administração, 32, 2008, Rio de Janeiro. Anais..., Rio de Janeiro: ANPAD, 2008. (CD ROM).

Gestão social: caso de inovação em políticas públicas ou mais um enigma de lampedusa? In: Encontro Nacional de Pesquisadores em Gestão Social, 3, 2009, Juazeiro/Petrolina. Anais..., Juazeiro/Petrolina: NIGS/UNIVASF, 2009. (CD ROM).

BRANDÃO, Carlos. Território e Desenvolvimento: as múltiplas escalas entre o local e o global. Campinas SP: Editora da Unicamp, 2012.

BRASIL. Lei № 11.977. Brasil, 2009.

Portaria № 21 de 22 de Janeiro de 2014. Ministério das Cidades, 2014.

CANÇADO, Airton. Fundamentos Teóricos da Gestão Social. Tese de Doutorado em Administração. Universidade Federal de Lavras, Lavras: UFLA, 2011.

. Gestão Social. In: BOULLOSA, Rosana (Org.). Dicionário para a formação em gestão social. Salvador: CIAGS/UFBA, 2014.

; PEREIRA, José R.; TENORIO, Fernando. Gestão Social: epistemologia de um paradigma. 1 ed. Curitiba: CRV, 2013.

; TENORIO, Fernando; PEREIRA, José R. Gestão Social: reflexões teóricas e conceituais. Cadernos EBAPE.BR, v. 9, o 3, artigo 1, Rio de Janeiro, Set. 2011.

CARDOSO, Adauto Lucio; LAGO, Luciana Corrêa. O Programa Minha Casa, Minha Vida e Seus Efeitos Territoriais. In: CARDOSO, Adauto Lúcio (org.) O Programa 
Minha Casa, Minha Vida e seus Efeitos Territoriais. Rio de Janeiro: Letra Capital, 2013.

DENALDI, Rosana. Política habitacional e urbana: avanços e impasses. 2012.

Disponível em:

<http://www.phdu.comuv.com/attachments/article/18/Pol\%C3\%ADtica\%20Habitacion al\%20e\%20Urbana\%20avan\%C3\%A7os\%20e\%20impasses\%20\%20-

20Rosana\%20Denaldi.pdf>. Acesso em: 29/09/2014.

DRUMOND, Alexandre Matos; SILVEIRA, Suely de Fátima R.; SILVA, Edson Arlindo da. Predominância ou coexistência? Modelos de administração pública brasileira na Política Nacional de Habitação. Revista de Administração Pública - Rio de Janeiro v. 48, n.1, p.3-25, jan/fev, 2014.

FISCHER, Tânia. SILVA, Francisco Raniere M. SOARES, Rodrigo Maurício. Bosque das Bromélias: mobilizações do presente, virtualidades do futuro - uma construção parentética. In: FERNANDES, Ana. LACERDA, Norma. PONTUAL, Virgínia. (org). Desenvolvimento, Planejamento e Governança: expressões do debate contemporâneo. 1 ed. Rio de Janeiro: Letra Capital / ANPUR, 2015.

FISCHER, Tânia. Poderes Locais, Desenvolvimento e Gestão: Introdução a uma Agenda. In: FISCHER, Tânia. (org.). Gestão do Desenvolvimento e Poderes Locais: Marcos Teóricos e Avaliação. Salvador: Casa da Qualidade, 2002.

. O Futuro da Gestão. HSM Management, v.10, n.64, set./out., 2007.

FRANÇA FILHO, Genauto. Definido Gestão Social. In: SILVA JR, Jeová; MÂISH, Rogério; CANÇADO, Airton. Gestão Social: Práticas em debate, teorias em construção. Fortaleza: Imprensa Universitária, 2008.

Gestão Social: um conceito em construção. In: Colóquio Internacional Sobre o Poder Local, IX, Salvador, 2003. Anais... Salvador: CIAGS/UFBA. (CD ROM).

HARVEY, David. Espaços de Esperança. Tradução de Adail Ubirajara Sobral e Maria Stela Gonçalves. São Paulo: Edições Loyola, 2004.

MARICATO, Ermínia. É a questão urbana, estúpido! In: MARICATO, Ermínia et al. Cidades Rebeldes: Passe Livre e as manifestações que tomaram as ruas no Brasil. São Paulo: Boitempo: Carta Maior, 2013. 
Habitação e cidade. 7. ed. São Paulo: Atual, 1997.

MARQUES, Eduardo; RODRIGUES, Leandro. O Programa Minha Casa Minha Vida na metrópole paulistana: atendimento habitacional e padrões de segregação.

Revista Brasileira de Estudos Urbanos e Regionais, v.15, n.2, 2013.

MOURA, Jéssica Morais de. O Programa Minha Casa, Minha Vida na Região Metropolitana de Natal: uma análise espacial dos padrões de segregação e desterritorialização. Urbe, Revista Brasileira de Gestão Urbana. v.6, n.3, p.339359, 2014.

NETO, Paulo Nascimento; MOREIRA, Tomás Antonio; SCHUSSEL, Zulma das Graças. Housing Policy. A Critical Analysis on the Brazilian Experience. TeMA: Journal of Land Use, Mobility and Environment, v.5, n.3, pp.65-76, 2012.

QUIRINO, Bruno et al. Análise do programa habitacional Minha Casa, Minha Vida nas perspectivas da inovação social e a evolução das políticas públicas. Revista de Gestão Social e Ambiental - RGSA, São Paulo, v. 9, n. 3, p. 97-117, set./dez., 2015

ROLNIK, Raquel. 10 Anos do Estatuto da Cidade: Das Lutas pela Reforma Urbana às Cidades da Copa do Mundo. 2013a. Disponível em: $<$ http://raquelrolnik.files.wordpress.com/2013/07/10-anos-do-estatuto-da-cidade.pdf> Acesso em: 23/11/2014.

Apresentação - As vozes das ruas: As revoltas de Junho e suas interpretações. In: MARICATO, Ermínia et al. Cidades Rebeldes: Passe Livre e as manifestações que tomaram as ruas no Brasil. São Paulo: Boitempo: Carta Maior, 2013b.

RIZEK, Cibele Saliba; AMORE, Caio Santo; CAMARGO, Camila Moreno de. Social policies, management and business in the production of cities: the program minha casa, minha vida - "entities". Cad. CRH, Salvador, v.27, n.72, p.531-546, dez. 2014. Disponível em http://www.scielo.br/scielo.php?script=sci arttext\&pid=S0103$49792014000300006 \&$ lng=pt\&nrm=iso. Acesso em 16 ago. 2016. http://dx.doi.org/10.1590/S0103-49792014000300006.

SANTOS, Milton. A natureza do espaço. São Paulo: Hucitec, 1999. 
SANTOS, Maria Elisabete. et al. O Programa Minha Casa Minha Vida (PMCMV) e o Direito à Moradia - a experiência dos sem-teto em Salvador. Organizações \& Sociedade, v.21, n.71, p. 713-734, 2014.

SAUNDERS, Doug. Cidade de Chegada - a migração final e o futuro do mundo. São Paulo: DVS Editora, 2013.

SOARES, Isabelle Oliveira et al. Interesses especulativos, atuação do Estado e direito à cidade: o caso do programa "Minha Casa Minha Vida" em Uberaba (MG). Urbe - Revista Brasileira de Gestão Urbana, v.5, n.1, p. 119-131, 2013.

TENÓRIO, Fernando. Gestão social: uma perspectiva conceitual. RAP, Rio de Janeiro, v.32, n.5, p.7-23, set/out, 1998.

. Tem razão a administração? 3 ed. ljuí: Editora da Unijuí, 2008.

(Org.). Cidadania e desenvolvimento local. Rio de Janeiro: FGV; ljuí: Ed.

Unijuí, 2007.

VAINER, Carlos. Quando a cidade vai às ruas. In: MARICATO, Ermínia [et al.]. Cidades Rebeldes: Passe Livre e as manifestações que tomaram as ruas no Brasil. São Paulo: Boitempo: Carta Maior, 2013. 